01,02

\title{
Электронная структура графена на карбиде кремния, интеркалированного атомами кремния и кобальта
}

\author{
(․ С.М. Дунаевский ${ }^{1,2}$, Е.Ю. Лобанова ${ }^{3, \uparrow, ~ Е . К . ~ М и х а и ̆ л е н к о ~}{ }^{1,2}$, И.И. Пронин $^{4}$ \\ ${ }^{1}$ Национальный исследовательский центр „Курчатовский институт“, \\ Петербургский институт ядерной фризики им. Б.П. Константинова, \\ Гатчина, Россия \\ ${ }^{2}$ Санкт-Петербургский государственный электротехнический университет „ЛЭТИ“, \\ Санкт-Петербург, Россия \\ ${ }^{3}$ Национальный исследовательский университет ИТМО, \\ Санкт-Петербург, Россия \\ ${ }^{4}$ Физико-технический институт им. А.Ф. Иофффе РАН, \\ Санкт-Петербург, Россия \\ ๑ E-mail: elobanova@itmo.ru
}

Поступила в Редакцию 16 фревраля 2021 г.

В окончательной редакции 16 февраля 2021 г.

Принята к публикации 18 февраля 2021 г.

\begin{abstract}
Представлены результаты ab initio расчетов спин-поляризованной зонной структуры графена на карбиде кремния, интеркалированного атомами кобальта и кремния. Показано, что атомы металла и кремния при интеркаляции локализуются между подложкой и буферным слоем атомов углерода. Изначально слой кобальта оказывается сильно связан с буферным слоем. Последующее интеркалирование кремния и образование силицида кобальта приводит к переходу от сильной гибридизации к формированию на поверхности системы квазисвободного двухслойного графена за счет превращения буферного слоя во второй слой графена.
\end{abstract}

Ключевые слова: графен на карбиде кремния, кобальт, интеркалирование, силициды, метод функционала плотности.

DOI: 10.21883/FTT.2021.06.50926.033

\section{1. Введение}

В современной электронике существует тенденция перехода к низкоразмерным системам, что требует создания новых функциональных материалов. Одним из таких материалов является графен. Он обладает рядом выдающихся свойств, которые делают его привлекательным как для фундаментальных исследований, так и для технологических применений $[1,2]$. Так, большая длина спиновой релаксации и слабое спин-орбитальное взаимодействие в графене позволяют рассматривать его как основу будущей спинтроники [2]. В этой связи особенно перспективными являются материалы на основе графена, ферромагнитных металлов и их силицидов. Показано, что графен не только защищает металлы от окисления, но и способствует сохранению в них перпендикулярной магнитной анизотропии в широком диапазоне толщин пленок $[3,4]$. Эта особенность может быть использована в устройствах магнитной памяти [5]. Другим потенциальным применением подобных интерфейсов является инжекция спин-поляризованных электронов [6]. Для реализации этой возможности материал должен обладать большой величиной спиновой поляризации. Такой особенностью обладают, например, силициды переходных металлов.
Одним из подходов к синтезу таких гибридных материалов является интеркаляция, то есть получение новых материалов путем внедрения атомов нужных веществ под графен. Интеркаляция позволяет синтезировать под графеном такие пленки, на которых прямой рост графена невозможен.

К настоящему моменту экспериментально изучен процесс интеркалирования графена, выращенного на карбиде кремния, переходными металлами $\mathrm{Fe}$ [7] и Co [8], и показано, что в зависимости от условий синтеза возможно формирование металлических пленок под графеном или твердого раствора металла в подложке. Также изучен процесс синтеза ферромагнитных силицидов под графеном путем его последовательного интеркалирования атомами кремния и металлов $[9,10]$. Показано, что такой способ синтеза позволяет получать под графеном силициды различной стехиометрии. При этом изменения электронной структуры графена, связанные с интеркалированием металлов и кремния, мало изучены как экспериментально, так и теоретически. Представленные в литературе сведения противоречивы. Так, в работах $[11,12]$ приведены данные фотоэлектронной спектроскопии с угловым разрешением для случая интеркаляции графена на карбиде кремния $(\mathrm{SiC})$ железом. Утверждается, что внедрение железа ведет к 


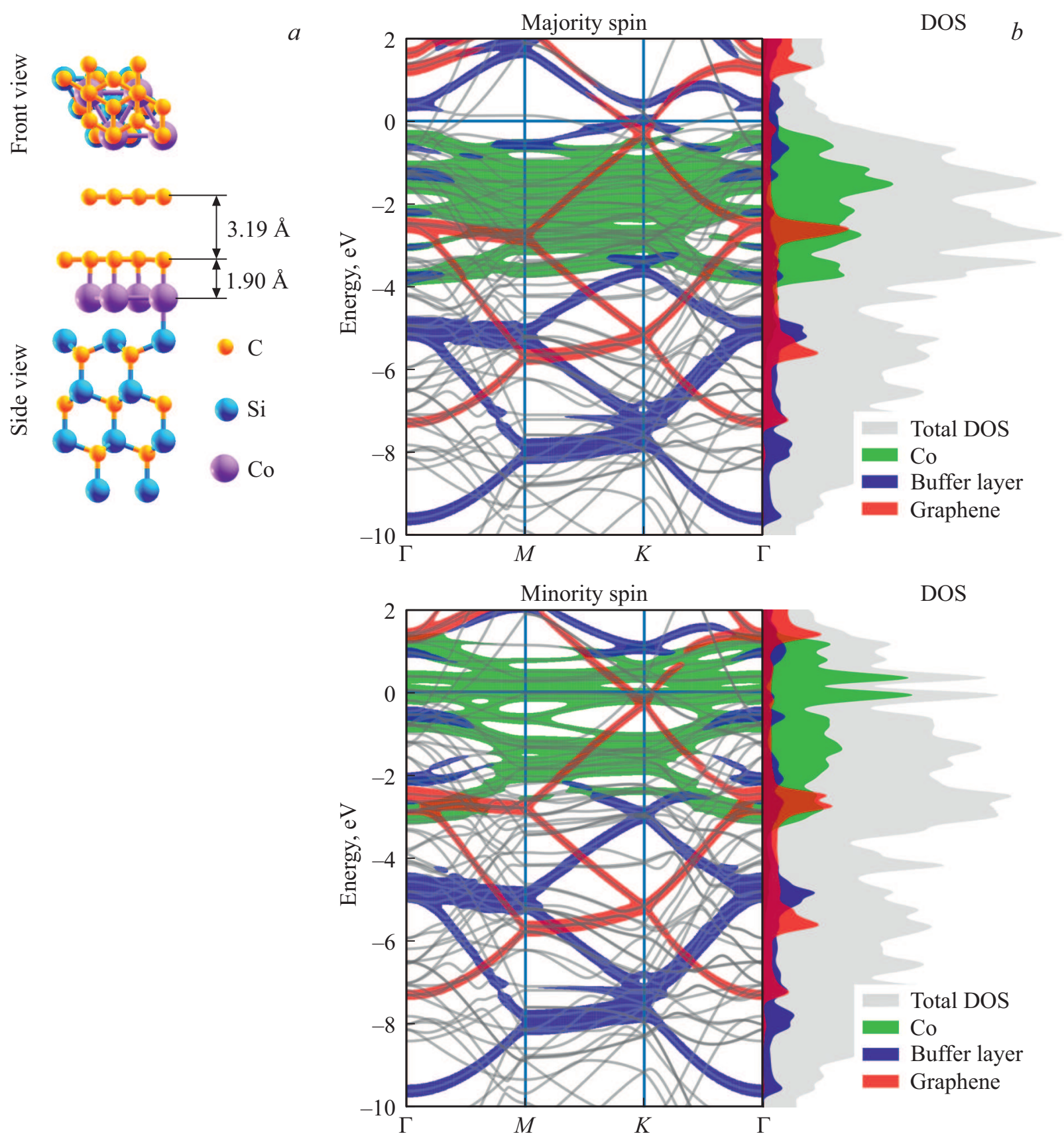

Рис. 1. Суперъячейка для моделирования системы graphene/Co/SiC $(a)$; спектр $E_{\sigma}(\mathbf{k})$ и вклады различных атомов в плотность состояний (DOS) в системе graphene/Co/SiC $(b)$.

разрыву связей буферного слоя с подложкой и, следовательно, формированию квазисвободного двуслойного графена на поверхности образца. Однако приведенные данные нельзя интерпретировать однозначно из-за отсутствия сведений о составе пленки, которая формируется под графеном при внедрении атомов железа. В [13] проведено теоретическое изучение электронной структуры графена на карбиде кремния, интеркалированного железом и показано, что гибридизация препятствует формированию двуслойного графена. Эти результаты совпадают с результатами [14], где рассмотрено влияние на электронную структуру системы не только железной пленки, но и силицида железа под графеном. Тем не менее, формирование под графеном силицидов железа и кобальта на $\mathrm{Ni}(111)$ делает графен квазисвободным, что подтверждается данными фотоэлектронной спектроскопии с угловым разрешением $[4,15]$. Для устранения этих противоречий в настоящей работе выполнены теоретические расчеты электронной структуры $E_{\sigma}(\mathbf{k})$ ферромагнитных пленок кобальта и его силицида под графеном, выращенным на карбиде кремния - graphene $/ \mathrm{Co} / \mathrm{SiC}$ и graphene $/ \mathrm{Si} / \mathrm{Co} / \mathrm{SiC}$. 

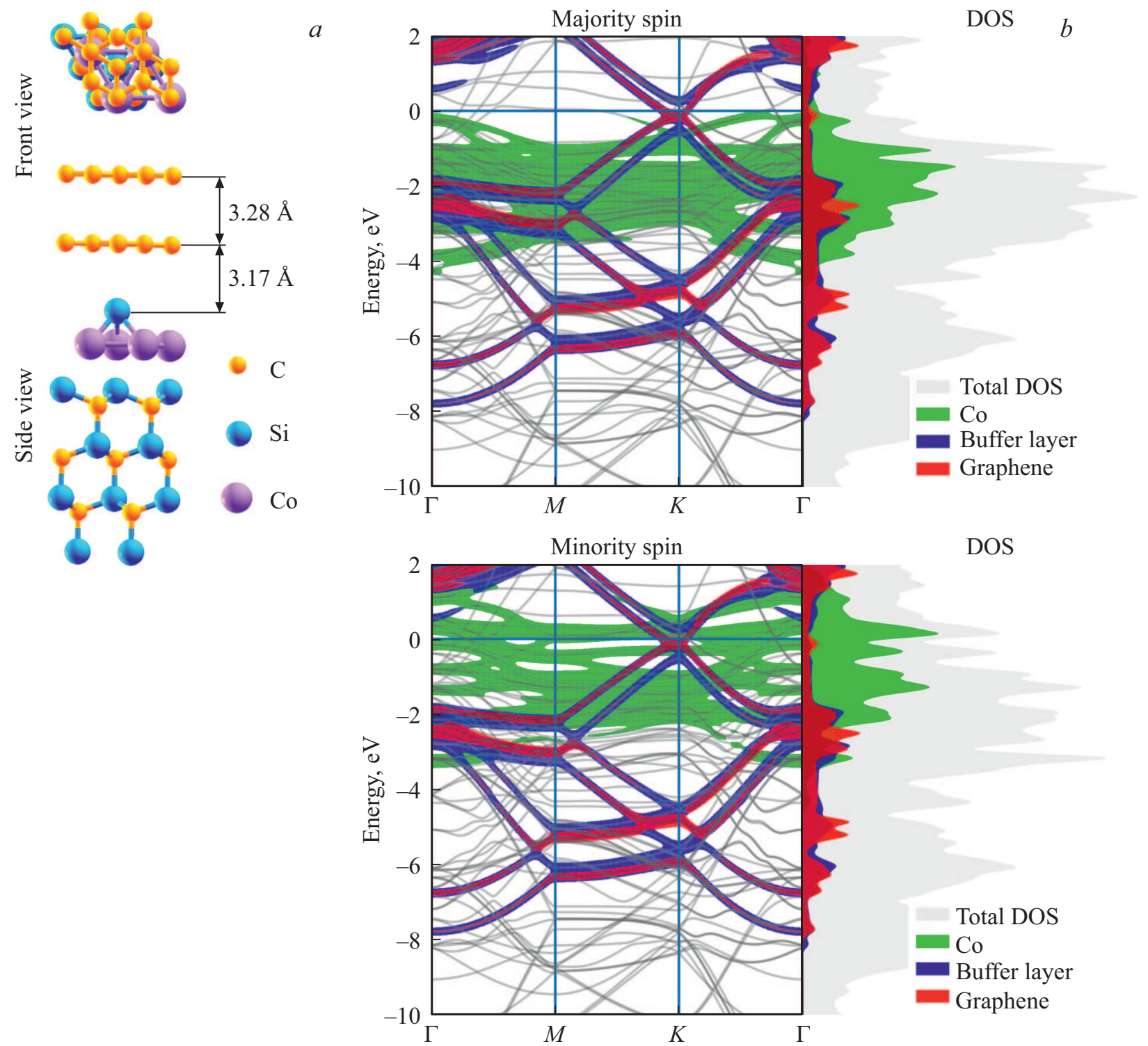

Рис. 2. Суперъячейка для моделирования системы graphene $/ \mathrm{Si} / \mathrm{Co} / \mathrm{SiC}(a)$; спектр $E_{\sigma}(\mathbf{k})$ и вклады различных атомов в плотность состояний (DOS) в системе graphene/ $\mathrm{Si} / \mathrm{Co} / \mathrm{SiC}(b)$.

\section{2. Методика расчетов}

Спин-поляризованные самосогласованные расчеты спектра $E_{\sigma}(\mathbf{k})$ проводились в рамках теории спинового функционала плотности (SDFT), реализованного в программном пакете Quantum ESPRESSO [16]. Для вычислений применялись PAW-псевдопотенциалы [17-18] и градиентное приближение обменно-корреляционного функционала [19-21]. Интегрирование в обратном пространстве [22] осуществлялось по сетке $8 \times 8 \times 1$ $k$-точек в зоне Бриллюэна. Максимальная кинетическая энергия плоских волн - 200 Rу. Для графена на карбиде кремния характерна реконструкция $\mathrm{p}(6 \sqrt{3} \times 6 \sqrt{3}) \mathrm{R} 30^{\circ}$, что соответствует $12 \times 12$ ячейкам графена. В расчетах „из первых принципов“ электронного спектра графена на карбиде кремния $\mathrm{SiC}$ обычно использу- ют модель, в которой на три поверхностные ячейки $\mathrm{SiC}(0001)(\sqrt{3} \times \sqrt{3})$ помещают четыре ячейки графена $(2 \times 2)$ [23]. Постоянная решетки свободного графена составляет $2.46 \AA$, а $\operatorname{SiC}(0001) 3.07 \AA$. Таким образом, несоответствие постоянных решетки при использовании этой модели составляет порядка 8\%. Уменьшить напряжение в системе позволяет одновременное растяжение графена и сжатие $\mathrm{SiC}$ на 4\%. В работе [24] показано, что это не приводит к значительным искажениям зонной структуры по сравнению с увеличенной суперъячейкой. Суперьячейка исходной системы состояла из четырех бислоев $\mathrm{SiC}$ (по три атома $\mathrm{Si}$ и С на слой) с графеном (8 атомов C) и буферным слоем (8 атомов C) на поверхности. Суперъячейка была транслирована как гексагональная решетка Браве с постоянной, равной $10.64 \AA$. Толщина вакуумного промежутка составляла 


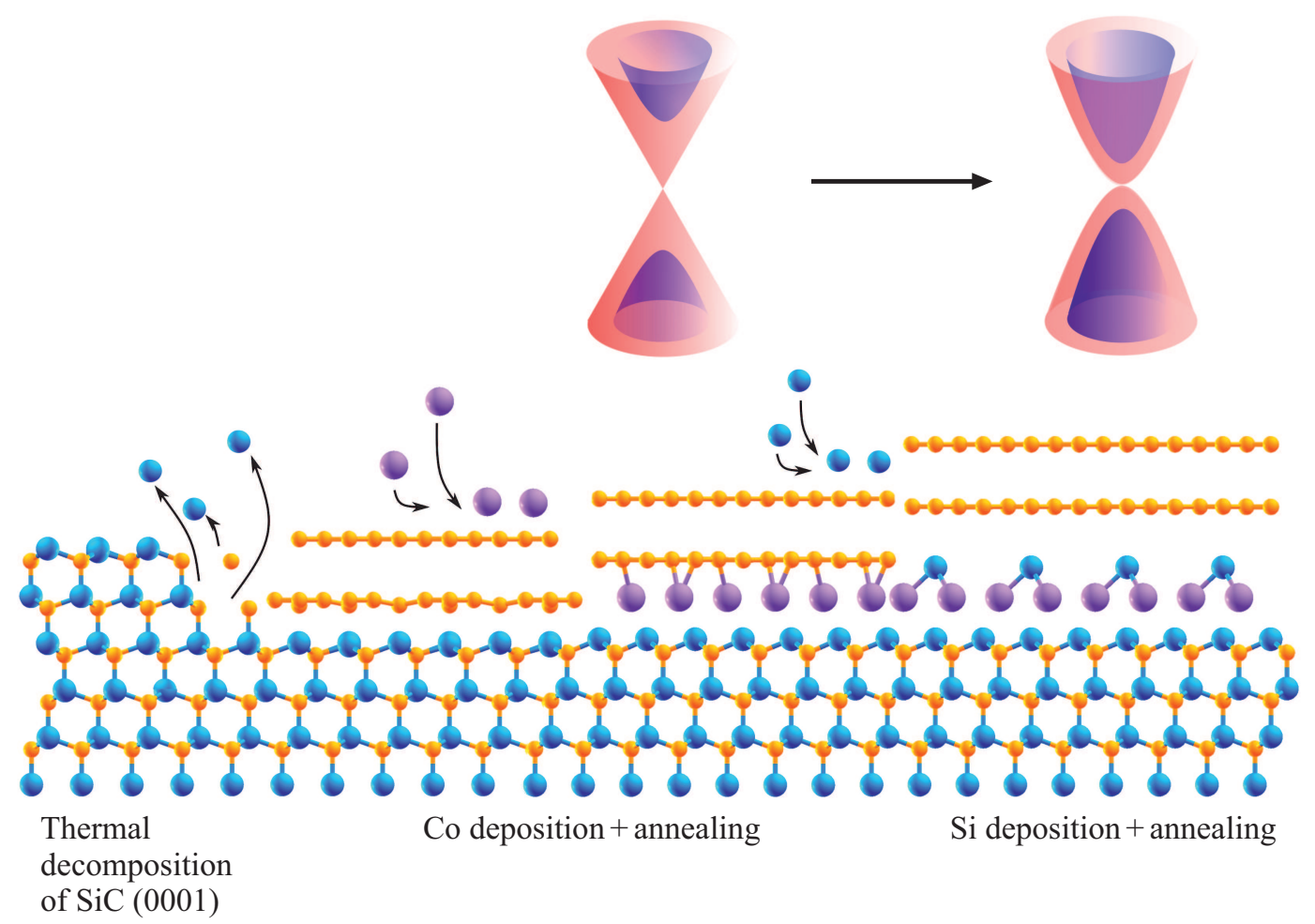

Рис. 3. Общая схема формирования интерфейса graphene $/ \mathrm{Si} / \mathrm{Co} / \mathrm{SiC}$ и сопутствующих изменений электронной структуры графена и буферного слоя.

16 А̊. Для конструирования новых суперъячеек в изначальную систему добавляли атомы кобальта и кремния. Оптимизация геометрии всех систем проводилась с учетом дисперсионного взаимодействия. Полученные положения атомов были использованы для самосогласованных расчетов зонной структуры. Для удобства интерпретации результатов было произведено разложение полученных волновых функций в базисе атомных орбиталей.

\section{3. Результаты и их обсуждение}

Сначала была установлена локализация интеркалируемых атомов кобальта. Для этого были проведены расчеты полной энергии систем с различным положением атома кобальта (на поверхности, между графеном и буферным слоем, между буферным слоем и подложкой). Сравнение энергии этих систем позволило установить, что интеркаляция кобальта под графен и буферный слой является энергетически выгодной.

Рассмотрим случай формирования чистой металлической пленки под графеном. В литературе хорошо исследован интерфейс graphene/Co(0001) [25]. Разница постоянных решетки графена и кобальта составляет порядка $1.5 \%$, что обеспечивает возможность эпитаксиального роста графена на грани $\mathrm{Co}(0001)$. Для этого случая известно относительное расположение атомов графена и кобальта (top-fcc). Рассмотрим систему, в которой в изначальную ячейку добавлены 4 атома кобальта таким образом, чтобы между буферным слоем и слоем Со получился аналог интерфейса graphene/Co(0001). Соответствующая суперьячейка показана на рис. 1, $a$. Оптимизация геометрии показывает, что разница между положением верхнего и нижнего атома буферного слоя составляет $0.09 \AA$. На рисунке расстояния отсчитываются от верхнего атома. Это означает, что буферный слой нельзя считать плоским. При этом расстояние между буферным слоем и кобальтом составляет всего $1.90 \AA$, что указывает на сильную связь буферного слоя с подложкой. Электронная структура системы графен $/ \mathrm{Co} / \mathrm{SiC}$ показана на рис. $1, b$. Конус Дирака графена расположен на $0.3 \mathrm{eV}$ выше уровня Ферми. Электронная структура буферного слоя искажена по сравнению с графеном из-за гибридизации с $d$-состояниями металла. Состояния буферного слоя расположены на 2.5 и на $3.0 \mathrm{eV}$ ниже уровня Ферми для разных проекций спина.

Суперьячейка для моделирования силицида кобальта под графеном на карбиде кремния была получена путем добавления в предыдущую суперъячейку атомов кремния (рис. 2,a). В этом случае расстояние между буферным слоем и подложкой составило уже $3.17 \AA$, что сравнимо с межслоевым расстоянием в графите. Увеличение расстояния между буферным слоем и подложкой свидетельствует об уменьшении межслоевого взаимодействия. Соответствующая электронная структура приведена на рис. $2, b$. Состояния $p_{z}$-электронов графена 

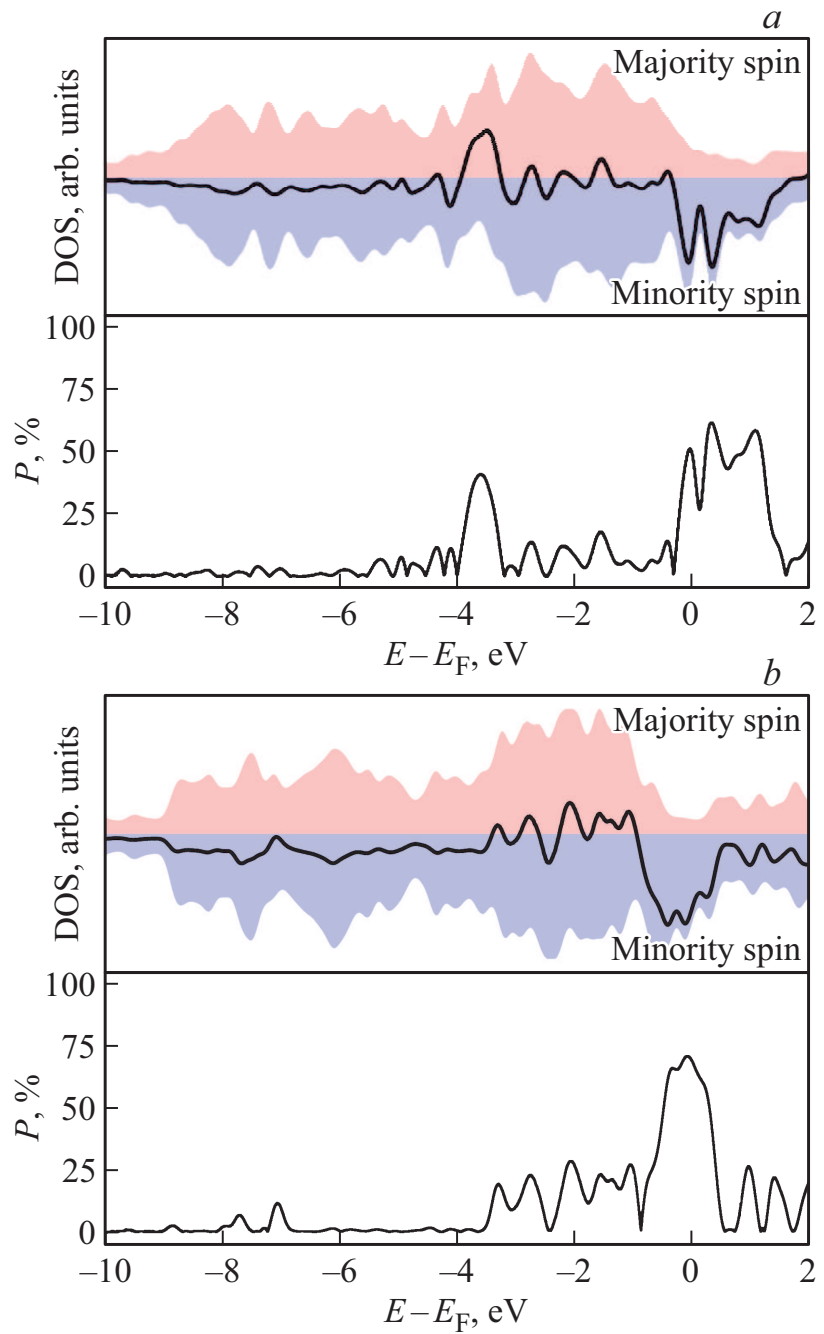

Pис. 4. Плотности состояний (DOS) и спиновая поляризация систем graphene $/ \mathrm{Co} / \mathrm{SiC}(a)$ и graphene $/ \mathrm{Si} / \mathrm{Co} / \mathrm{SiC}(b)$.

и буферного слоя в этом случае формируют двойную параболу на уровне Ферми в окрестности точки $K$. Такой вид энергетических зон характерен для двуслойного графена. Спиновая поляризация электронной структуры для обоих рассмотренных случаев определяется наличием магнитных атомов кобальта.

В общем случае взаимодействия графена с металлом происходит гибридизация $p_{z}$ состояний углерода с $d$-состояниями металла. При этом линейная дисперсия $d$-состояний графена искажается. Этот же механизм отвечает за взаимодействие буферного слоя с интеркалированным кобальтом. Так, расположение точки Дирака буферного слоя для системы со монослоем кобальта совпадает с положением точки Дирака графена в системе graphene/Co/Ni(111) [3]. В то же время дополнительное внедрение атомов кремния и формирование интерфейca graphene $/ \mathrm{Co}_{3} \mathrm{Si} / \mathrm{Ni}(111)$ приводило к восстановлению линейной дисперсии $\pi$-состояний графена. Зная это, можно ожидать, что в системе graphene $/ \mathrm{Si} / \mathrm{Co} / \mathrm{SiC}$ буферный слой окажется преобразован во второй слой графена, и, следовательно, в спектре электронной структуры проявятся состояния с параболической дисперсией, характерные для двуслойного графена. Именно этот случай наблюдается в электронной структуре силицида кобальта под графеном на карбиде кремния (рис. 2, $b$ ). Таким образом, синтез силицида кобальта и сопровождающих его изменений электронной структуры можно изобразить в виде схемы, представленной на рис. 3. После синтеза графена на $\mathrm{SiC}$ и его интеркаляции атомами кобальта буферный слой оказывается лежащим на металлической пленке. Взаимодействие буферного слоя с подложкой сопровождается сильной гибридизацией. Графен при этом является квазисвободным. В его электронной структуре имеются участки с линейной дисперсией $\pi$-состояний в виде конуса Дирака. После интеркаляции атомов кремния буферный слой релаксирует и преобразуется во второй слой графена. В силу слабого взаимодействия двуслойного графена с силицидом кобальта, он также оказывается квазисвободным. Поэтому электронная структура преобразуется из конуса Дирака графена со вложенными гибридизированными состояниями буферного слоя в двойной параболоид двуслойного графена.

Для исследуемых систем было получено распределение магнитных моментов по слоям. Как и ожидалось, намагниченность сосредоточена в слоях ферромагнетика. Средний магнитный момент атомов кобальта в системе graphene $/ \mathrm{Co} / \mathrm{SiC}$ составил $1.31 \mu \mathrm{B}$, в системе graphene $/ \mathrm{Si} / \mathrm{Co} / \mathrm{SiC} 1.26 \mu \mathrm{B}$. При этом во втором случае наблюдается также небольшое подмагничивание атомов кремния $(-0.2 \mu \mathrm{B})$. Для оценки перспективности материала для применений в спинтронных устройствах также важна спиновая поляризация вблизи уровня Ферми. Она отражает несимметричность распределения электронной плотности для разных спинов. Величина спиновой поляризации $P$ вычислялась по формуле

$$
P=\frac{n_{\uparrow}-n_{\downarrow}}{n_{\uparrow}+n_{\downarrow}},
$$

где $n^{\uparrow}$ и $n_{\downarrow}-$ плотности состояний для электронов с разными проекциями спина. Соответствующие зависимости приведены на рис. 4. На уровне Ферми величина спиновой поляризации составляет 51 и 65\% для металлической и силицидной пленки под графеном соответственно. Дальнейшее увеличение спиновой поляризации возможно при синтезе под графеном полуметаллических сплавов Гейслера на основе силицидов железа и кобальта.

\section{4. Заключение}

Отличительной особенностью графена на карбиде кремния является наличие буферного слоя атомов углерода. В процессе интеркаляции такого графена атомами кобальта и кремния они локализуются между буферным слоем и подложкой. Таким образом, интеркалированный 
ферромагнитный слой взаимодействует не с графеном, а с буферным слоем. Проведенные в настоящей работе первопринципные расчеты позволили получить новые сведения о том, как трансформируется электронная структура буферного слоя и графена при последующей интеркаляции системы graphene/SiC кобальтом и кремнием.

Проведена геометрическая оптимизация систем graphene $/ \mathrm{Co} / \mathrm{SiC}$ и graphene $/ \mathrm{Si} / \mathrm{Co} / \mathrm{SiC}$, получены их электронные структуры и плотности состояний. Показано, что внедрение атомов кобальта сопровождается гибридизацией $d$-состояний кобальта и $p$-состояний буферного слоя. Дальнейшее внедрение атомов кремния приводит к образованию силицида кобальта, что способствует ослаблению гибридизации и, как следствие, взаимодействия буферного слоя с подложкой, что влечет за собой формирование на поверхности системы квазисвободного двуслойного графена. Таким образом, буферный слой из сильно связанного с металлом углеродного слоя при интеркаляции кремния превращается во второй слой графена. Этим, по всей видимости, объясняется появление двуслойного графена при интеркаляции металлов в некоторых экспериментальных работах $[11,12]$ : в формировании силицида при высокотемпературной интеркаляции и последующем отжиге может принимать участие кремний подложки $(\mathrm{SiC})$.

Также в работе найдено распределение магнитных моментов в исследуемых системах. Намагниченность сосредоточена в ферромагнитных слоях. Величина спиновой поляризации составляет $51 \%$ для системы graphene $/ \mathrm{Co} / \mathrm{SiC}$ и $65 \%$ для системы graphene $/ \mathrm{Si} / \mathrm{Co} / \mathrm{SiC}$. Полученные данные указывают на перспективность применения структур на основе графена на карбиде кремния и ферромагнитных металлов в спинтронике.

\section{Благодарности}

Авторы статьи выражают благодарность центру обработки данных НИЦ „Курчатовский институт“ - ПИЯФ за предоставленные ресурсы.

\section{Конфликт интересов}

Авторы заявляют, что у них нет конфликта интересов.

\section{Список литературы}

[1] K.S. Novoselov, D.V. Andreeva, W. Ren, G. Shan. Front. Phys. 14, 1, 13301 (2019).

[2] X. Lin, W. Yang, K.L. Wang, W. Zhao. Nature Electron. 2, 7, 274 (2019).

[3] С.М. Дунаевский, Е.Ю. Лобанова, Е.К. Михайленко, И.И. Пронин. ФТТ 6, 7, 1368 (2019).

[4] G.S. Grebenyuk, O.Yu. Vilkov, A.G. Rybkin, M.V. Gomoyunova, B.V. Senkovskiy, D.Yu. Usachov, D.V. Vyalikh, S.L. Molodtsov, I.I. Pronin. Appl. Surf. Sci. 392, 715 (2017).
[5] A.A. Rybkina, A.G. Rybkin, I.I. Klimovskikh, P.N. Skirdkov, K.A. Zvezdin, A.K. Zvezdin, A.M. Shikin. Nanotechnology 31, 16165201 (2020).

[6] S. Li, K.V. Larionov, Z.I. Popov, T. Watanabe, K. Amemiya, S. Entani, P.V. Avramov, Y. Sakuraba, H. Naramoto, P.B. Sorokin, S. Sakai. Adv. Mater. 32, 61905734 (2020).

[7] М.В. Гомоюнова, Г.С. Гребенюк, В.Ю. Давыдов, И.А. Ермаков, И.А. Елисеев, А.А. Лебедев, С.П. Лебедев, Е.Ю. Лобанова, А.Н. Смирнов, Д.А. Смирнов, И.И. Пронин. ФТТ 60, 7, 1423 (2018).

[8] G.S. Grebenyuk, E.Yu. Lobanova, D.A. Smirnov, I.A. Eliseev, A.V. Zubov, S.P. Lebedev, V.Yu. Davydov, A.A. Lebedev, I.I. Pronin. Phys. Solid State 61, 1316 (2019).

[9] G.S. Grebenyuk, I.A. Eliseev, S.P. Lebedev, E.Y. Lobanova, D.A. Smirnov, V.Y. Davydov, A.A. Lebedev, I.I. Pronin. Phys. Solid State 62, 3, 462 (2020).

[10] G.S. Grebenyuk, I.A. Eliseev, S.P. Lebedev, E.Y. Lobanova, D.A. Smirnov, V.Y. Davydov, A.A. Lebedev, I.I. Pronin. Phys. Solid State 62, 10, 1944 (2020).

[11] S.J. Sung, J.W. Yang, P.R. Lee, J.G. Kim, M.T. Ryu, H.M. Park, G. Lee, C.C. Hwang, Kwang. S. Kim, J.S. Kim, J.W. Chung. Nanoscale 6, 382 (2014).

[12] K. Shen, H. Sun, J. Hu, J. Hu, Z. Liang, H. Li, Z. Zhu, Y. Huang, L. Kong, Y. Wang, Z. Jiang, H. Huang, J.W. Wells, F. Song. J. Phys. Chem. C 122, 21484 (2018).

[13] E.Y. Lobanova, I.I. Pronin. J. Phys.: Conf. Ser. 1400, 5, 055047 (2019).

[14] X. Luo, G. Liang, X. Sun, Y. Li, F. Yu, L. Wei, X. Cheng, L. Sun, X. Zhao. Carbon. 156, 187 (2020).

[15] G.S. Grebenyuk, S.M. Dunaevsky, E.Yu. Lobanova, D.A. Smirnov, I.I. Pronin. Appl. Surf. Sci. 470, 840 (2019).

[16] P. Giannozzi, O. Andreussi, T. Brumme, O. Bunau, M.B. Nardelli, M. Calandra, R. Car, C. Cavazzoni, D. Ceresoli, M. Cococcioni, N. Colonna. J. Phys.: Condens. Matter 29, 465901 (2017).

[17] D. Vanderbilt. Phys. Rev. B 41, 7892 (1990).

[18] P.E. Blöchl, Phys. Rev. B 41, 5414 (1990).

[19] J.P. Perdew, J. Chevary, S. Vosko, K.A. Jackson, M.R. Pederson, D. Singh. Phys. Rev. B 46, 11, 6671 (1992).

[20] A.D. Becke. Phys. Rev. A 38, 3098 (1988).

[21] D.C. Langreth, M.J. Mehl. Phys. Rev. B 28, 1809 (1983)

[22] H.J. Monkhorst, J.D.Pack. Phys. Rev. B 13, 5188 (1976).

[23] A. Mattausch, O. Pankratov. Phys. Rev. Lett. 99, 7, 076802 (2007).

[24] F. Varchon, R. Feng, J. Hass, X. Li, B.N. Nguyen, C. Naud, L. Magaud, Phys. Rev. Lett. 99, 12, 126805 (2007).

[25] D. Marchenko, A. Varykhalov, J. Sánchez-Barriga, O. Rader, C. Carbone, G. Bihlmayer. Phys. Rev. B 91, 23, 235431 (2015).

Редактор К.В. Емцев 